\title{
Digital Competence: A Multi-dimensional Conceptualization and a Typology in an SME Context
}

\author{
Dragos Vieru \\ University of Québec \\ dragos.vieru@teluq.ca \\ Simon Bourdeau \\ UQAM \\ bourdeau.simon2@uqam.ca
}

\author{
Amélie Bernier \\ University of Québec \\ amelie.bernier@teluq.ca
}

\author{
Séverin Yapo \\ University of Québec \\ severin.yapo@teluq.ca
}

\begin{abstract}
Small and medium-sized enterprises (SMEs) need to rely on information and communication technologies (ICT) to survive in the digital economy. Although the literature emphasizes the link between individual digital competence $(D C)$ and ICT use and adoption, there is a lack of understanding of how DC can be conceptualized in an SME context. Drawing on the existing literatures on SMEs and DC and on the change agentry perspective, this exploratory study proposes a multi-dimensional conceptualization of DC and advances a typology of three DC archetypes of SME employees: Technical Expert, Organizer, and Campaigner. We provide results from a multi-case study of three Canadian SMEs suggesting that the development of $D C$ should take into consideration the complementarity nature of the technological, social and cognitive aspects of the DC in order to successfully implement new technologies in SMEs.
\end{abstract}

\section{Introduction}

To be competitive SMEs need to develop new business strategies and processes involving the utilization of ICT [15]. It has been shown that the ability of SME businesses to innovate relies on investments made in ICT platforms, the success of which, in turn, depends on employees having expertise and the appropriate competences to maximize the ICT use [22]. The literature suggests that SMEs, in general, have reduced human and financial resources and are therefore likely to be less ready to adopt new ICT and change their business strategies [11]. A review of extant literature reveals that, in order for SMEs to benefits from ICT, SME employees needs to better understand the challenges confronting SMEs that hinder the adoption and use of ICT. Thus, SME employees need to have the proper digital competence (DC) [8]. The ability to align business strategies with existing ICT skills was found to have a significant impact on the level of ICT adoption and use in a SME [16]. On one hand, SMEs need to adopt ICT strategies to keep up with the digital economy. On the other hand, they lack employees with appropriate DC. But, how do SMEs' managers know what DC their employees have or need to have? The lack of a precise understanding of what DC is represents a significant challenge in determining if SMEs are capable to compete in the digital economy [2].

Competence in general is a widely used concept, which represents different things to different people. The Oxford English Dictionary [28] defines it as "the ability to do something successfully or efficiently". This is a broad definition, which may explain why competence has been conceptualized as an umbrellatype of notion wrapping almost every attribute that might influence performance [5]. In the context of a 21 st century digitized society, DC is an essential life asset [1] which represents a "set of knowledge, skills, attitudes, abilities, strategies, and awareness that are required when using ICT and digital media to perform tasks; solve problems; communicate; manage information; collaborate; create and share content; and build knowledge effectively, efficiently, appropriately, critically, creatively, autonomously, flexibly, ethically, reflectively for work, leisure, participation, learning, and socialising" $[15, \mathrm{p} .43]$. This long and detailed definition suggests that DC covers more than the plain know-how and technical skills usually associated with ICT competence in an organizational context and accentuates the idea that DC must also take into consideration contextual/social aspects and be complemented by cognitive and socio-emotional knowledge, skills and attitude [1].

The information systems (IS) literature on SMEs provides evidence that different levels of ICT competence in the organizations studied are related to different levels of accumulated individual ICT skills and knowledge in the organization. In particular, the development of internal ICT skills combined with 
management's knowledge and attitudes towards ICT adoption and use create the competences required to achieve higher levels of success with ICT use in SMEs [12]. In the last two decades, much of the research in IS had adopted a more technical perspective [26] and has focused on identifying: 1) business managers technical skills [5]; 2) ICT specialists knowledge and skill [32]; or 3) ICT professionals' personality characteristics [3]. One thing that should be highlighted, is that most past IS studies on individual DC had a relatively narrow and specific conceptualization of user [25]. This approach is not wrong, however, in the $21^{\text {st }}$ century, this perspective is too limited and tends to put more emphasis on technological aspects of ICT use and limiting consideration of other aspects, such as social environment sensibility and cognitive capabilities, on effective use of ICT [7].

All these definitions of DC have one commonality: they all portray DC as a multidimensional. Some conceptualizations tend to emphasize the practical and technical aspects of using ICT [26], while others suggest that developing DC necessitates a focus on the acquisition of higher order thinking skills [15] in various areas [9]. ICT are more and more ubiquitous and the use of such technology is now spread across the different types of jobs, organizations' levels and to accomplish a multitude of various tasks. However, as suggested by Lamb and Kling [25] researchers should not only consider ICT user (i.e. "the active agent in information system use") as such, but more as social actors who are "simultaneously enabled and constrained by the socio-technical affiliations and environments of the firm, its members, and its industry" [25, p.218]. Thus, since SME employees are social actors who have to play many different roles [25], the responsibility of "technology forecasting" as well as introducing and using new ICT is often shared by all the employees of a SME [6]. In such a situation, each SME employee has to become an agent of organizational change [27]. Jones-Evans [24] has shown how important specific SME employees are "in influencing the success of the small technology-based venture which they initiated (p.15)" and how these employees eventually influence ICT use.

In sum, extant literature on DC provides a myriad of different conceptualizations of DC and reveals a scattered image that falls short of providing the clarity needed by scholars and managers alike to understand the multidimensional nature of this concept. Also the literature on SMEs falls short of specifying what type of DC SME employees needs to have. Considering this gap in the literature, this study aims to propose a more encompassing conceptualization of DC. More specifically, we address the following research questions:

How can digital competence be conceptualized? Do different digital competence archetypes exist in SME? If so, how can they be characterized?

We draw on the existing body of research on SMEs and various DC definitions and on the change agentry perspective to propose a DC typology in the SME context. To do this, three key competence areas, i.e., technological, cognitive and social along with their learning domains, i.e. skill (know-how), knowledge (know-what) and attitude (know-why) are assembled in a theoretical framework. We then theorize about how different combinations of competence areas and learning domains are related to ICT adoption and use in the SME context and propose a typology of SME employees' DC archetypes. These archetypes are empirically tested in three case studies of Canadian SMEs.

Our study provides "an explanation of how, why, and when things happened, relying on varying views of causality and methods for argumentation" [18, p.619] and proposes a theoretical tool that enables readers to develop a broad understanding of a typology of DC in an SME context. Engaged in a theory-building effort, we put "less emphasis on the synthesis of prior literature and more emphasis on theoretical development" [31, p. iv] $]^{1}$.

\section{Theoretical Development 2.1 Digital Competence Conceptualization}

In an organizational context, a competence is either an organizational attribute, which encompasses individual skills and collective knowledge of the members of the organization, or an individual attributes. The IS literature suggests the more knowledge an organization has about technological innovations, the more likely it will be to adopt and use technological innovations. While at the organizational level the extant literature presents several studies in which researchers advance a variety of ICT management competencies [e.g., 30], at the individual level [e.g., 4, 5], the researchers focused on specific ICT competences of managers and IS professionals. For instance, at the organizational level, ICT competence represents "the extent to which a firm is knowledgeable about and effectively utilizes IT tools to manage information with the firm" [30, p.204]. At the individual level, such general and encompassing definition and operationalization does not exist. Thus,

\footnotetext{
${ }^{1}$ Due to space limitation, the complete details of the literature review are not presented in this short version of the article.
} 
the extant literature proposes a myriad of variants of DC applied in different contexts. However, this generates confusion when one tries to compare and integrate research findings, to explain in a unified definition what individual DC exactly is and how one should integrate and compare its imbricated dimensions.

It has been suggested that knowledge, skills and attitudes are the three learning domains underlying DC [e.g., 15, 5, 19]. At the conceptual level, since competences are sensitive to the organizational context $[11,19]$, a conceptual definition of DC should identify the main competence areas and the main learning areas associated with the specificities of a particular context. In our view, it would not be reasonable to think of a unique set of $\mathrm{DC}$, acceptable at all times and in all organizational contexts that are usually characterized by idiosyncratic practices, norms, and values. Thus, at the conceptual level, DC should remain stable while at the operationalized level, regular adaptations and revisions should be carried to align with specific settings and follow the changes in technical environment and social practices [13].

Thus, we consider DC as a multidimensional concept illustrated by a set of knowledge, skills and attitudes needed to be functional in an organizational digital environment. Its acquisition and possession in an organizational context may enable individuals to adapt to new practices and norms requirements set by the evolving ICT [4, 5]. These practices entail contextual knowledge and certain beliefs and values about ICT. In other words, ICT needs to be appropriated by social actors that engage in the role of change agent $[7,25]$. Based on the above argumentation, we propose the following conceptualization of individual DC:

Digital competence is an individual capacity to use and combine one's knowledge (i.e., know-what), skill (i.e. know-how), and attitude (i.e. know-why) associated with three related competence areas, technological, cognitive and social, to use new or existing ICT to analyze, select and critically evaluate information in order to investigate and solve workrelated problems and develop a collaborative knowledge base while engaging in organizational practices within a specific organizational context.

The multi-dimension conceptualization of the DC is illustrated in Figure 1. The proposed conceptualization of DC entails a critical understanding of three complementary and co-existing areas of application or competence areas, i.e. technological, cognitive and social. The technological area is underpinned by the knowledge, skills and attitude needed to explore new technological contexts and face technological problem in a flexible way [15, 9] such as solving problems when the ICT used does not work, selecting the most suitable ICT solution and recognising and using icons and interfaces of particular ICT [15]. Thus, example of technological knowledge could include knowledge about hardware, software applications, networks, social media, etc. [23]. Technological skills could include, for example, the ability to use common software tools or specialized tools supporting business tasks, the ability to exploit opportunities provided by ICT, notably the Internet or the ability to execute the technical operation aspects of digital tools [1].

The cognitive area is underpinned by the knowledge, skills and attitude needed to "read, select, interpret and evaluate data and information taking into account their pertinence and reliability" [9, p.187]. The cognitive area is related with access to, organization of and evaluation of information. It includes "tasks on linguistic and numeric competences applied to the digital word" $[15$, p.56], dealing with text, organizing data, evaluating information, selecting and interpreting graphs [9]. Example of cognitive skills include "general literacy, such as reading and numeracy, as well as critical thinking and problem solving" [23, p.1].

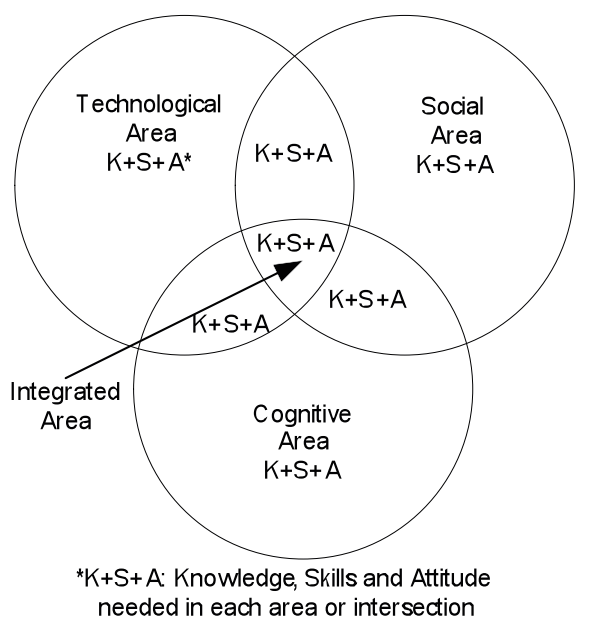

\section{Figure 1. Individual Digital Competence: A Multi-area Conceptualization}

The social area is underpinned by the knowledge, skills and attitude needed to interact with other individuals collaboratively using available ICT along the line of the existing organizational work norms and values [9]. In addition, the social area is concerned with issues related to responsible, ethical and safe use of ICT as well as to risks awareness, privacy, property rights and social media exposure [15]. Thus, examples of social skills include "effectively express and communicate, understanding the potential and 
limitations of each type of media [...] collaboration with possibly global reach, construct and maintain a system of personal communication links with relevant people and networks, extending social and professional networks outside the physical environment, [...] participate in digital activities", etc. [1, p.51].

The integrated area represents the overlapping zone of the three main areas and is underpinned by the knowledge, skills, and attitude needed to adopt and use ICT in organizational practices and collaboratively build new knowledge bases. This means that the integration between the three areas encompasses the competences needed for collaborative work and requires that individuals understand "the potential offered by technologies which enable individuals to share information and collaboratively build new knowledge" $[15$, p.55].

\subsection{An Integrative View of Digital Competence}

Various definitions of the three learning domains (i.e. knowledge, skills and attitude) have been proposed in different literatures, e.g. IS, SME, organization behavior, organization learning, etc. However, such diversity of definitions has created some confusion about what exactly each of these concepts means. Thus, since these concepts are central to the proposed DC conceptualization and that our objective is not to redefine these concepts, we use and adapt general definitions presented in previous studies to the context of DC (Table 1).

Ferrari [15] argues that DC covers much more than technical skills and depict seven competence domains of application (see Table 2) that individual should master in order to adapted to the current needs of modern organizations. Table 2 also shows how the seven key competence domains of application are captured by the proposed DC conceptualization (combination of three competence areas and three learning domains).

\subsection{A Typology of Digital Competence in SMEs}

The three learning domains and the three competence areas in our DC conceptualization are complementary and can be combined in various ways. Each specific combination can describe a particular archetype of DC [13]. By taking into consideration the social area and its relation with the technological and the cognitive areas, the DC conceptualization takes a change agentry perspective [25, 34], which is more encompassing than the narrower perspective of user taken in previous studies [e.g. 26]. Thus, we use Figure 1 to develop a typology of SME employees DC archetypes [13, 17]. In order to describe a complex organizational phenomenon such as DC profiles or archetypes, and its influence on ICT adoption and use, several researchers have advocated the development of typologies and typological theories [17]. Typological theories address complex phenomena without oversimplifying them, take into account holistic principles of inquiry and equifinality (i.e., the same outcome being attained via different pathways) and identify the pathways connecting particular archetypes to specific outcomes, such as ICT adoption and use [17]. A typology identifies multiple ideal types or archetypes which are "[...] complex constructs that can be used to represent holistic configurations of multiple unidimensional constructs" [13, p.233] and these archetypes are posited to be maximally effective. In a typological theory, archetypes must be defined by specifying, empirically and/or theoretically, multivariate profiles [17]. A major challenge underlying the development of a typological theory of DC in SME is to theoretically identify different DC profiles that are possible, i.e. a typology of DC archetypes [17]. Thus, since SME employees can be considered as change agent, we drew upon past research on the change agentry perspective as a theoretical foundation to do so [27]. According to Hirschhorn (2002), organizations that want to stay alive must constantly change to adapt to their moving environment. He suggested that, to be successful, change agents need to systematically employ three distinct, but related change approaches: the political campaign, to create a strong coalition and to get support; the marketing campaign, to communicate key messages, such as the benefits and themes, and to get into the thoughts and feelings of employees; and the military campaign, to organize and deploy scarce resources. In this vein, Markus and Benjamin [27] propose three models of change agentry: traditional, facilitator and advocate.

Each of these models characterizes the dominant beliefs underlying a change agent's behaviors and provides “... a basic orientation toward goals and means of IS work that shapes what the practitioner does and how she or he does it" [27, p.387]. Thus, the three models reflect archetypes (not empirical categories) and can be used to characterize the underlying DC associated with each model in relation to ICT adoption and/or use in SME [27, 19]. Similarly, Hirschheim and Klein [20] identified four dominant patterns of core assumptions, or archetypes, to characterize IS specialists' assumptions and influence their behaviors: expert, facilitator, social warrior and emancipator. Parallels between the facilitator models of Markus and Benjamin [27] and Hirschheim and 
Klein [20], as well as the political and marketing campaigns of Hirschhorn [21] can also be identified. Overlaps also exist between the advocate [27], the social warrior [20] and the military campaign [21].

Table 3 summarizes the characteristics of the three proposed DC archetypes: Technical Expert, Organizer, and Campaigner. Based on this description and using the DC conceptualization, it could be possible to hypothesize that the knowledge, skills and attitudes of a "technical expert" change agent would predominantly be related to the technological area rather than the social or cognitive area. It does not mean that the DC of the "technical expert" change agent would have no knowledge, skill and attitude related to the social and cognitive area.

Table 1. Digital Competence: Learning Domains Definitions

\begin{tabular}{|c|l|c|c|}
\hline Domains & \multicolumn{1}{|c|}{ Definition } & Source \\
\hline Knowledge & $\begin{array}{l}\text { Facts, information, principles, theories and practices acquired through experience and/or education, } \\
\text { i.e. the theoretical or practical understanding of the nature, role and opportunities of ICT in everyday } \\
\text { contexts such as, for example, using computer applications, understanding of the opportunities and } \\
\text { potential risks of Internet and social media, information sharing and collaborative networking, etc. }\end{array}$ & {$\left[\begin{array}{l}{[1,28,} \\
5]\end{array}\right.$} \\
\hline \multirow{3}{*}{ Skills } & $\begin{array}{l}\text { The ability to apply knowledge to complete tasks; to solve problems; to search, collect and process } \\
\text { complex information and; to produce, present and understand it, using ICT, in a critical and } \\
\text { systematic way. }\end{array}$ & {$[1,28$,} \\
\hline \multirow{2}{*}{ Attitude } & $\begin{array}{l}\text { The ways of thinking and the motivations for acting that shape people's action in digital } \\
\text { environments such as intercultural, collaborative, critical, creative, responsible and autonomous } \\
\text { aspects. For example, they include ethics, values, and priorities. }\end{array}$ & {$[1,15]$} \\
\hline
\end{tabular}

Table 2. An Integrative View of Digital Competence (adapted from [19])

\begin{tabular}{|l|l|l|}
\hline $\begin{array}{c}\text { Domains of } \\
\text { Application }\end{array}$ & \multicolumn{1}{|c|}{$\begin{array}{c}\text { Digital Competence Areas } \\
\text { (Figure 1) }\end{array}$} & Description \\
\hline $\begin{array}{c}\text { 1. Information } \\
\text { Management }\end{array}$ & $\begin{array}{l}\text { Intersection of Technological } \\
\text { and Cognitive areas }\end{array}$ & Identify, locate, access, retrieve, store and organize information. \\
\hline $\begin{array}{l}\text { 2. Collaboration } \\
\text { Social area }\end{array}$ & $\begin{array}{l}\text { Link to others, participate in online networks and communities, } \\
\text { and interact constructively and with a sense of responsibility. }\end{array}$ \\
\hline $\begin{array}{c}\text { 3. Communication and } \\
\text { sharing }\end{array}$ & $\begin{array}{l}\text { Intersection of Technological } \\
\text { and Social areas }\end{array}$ & $\begin{array}{l}\text { Communicate through online tools, taking into account privacy, } \\
\text { safety and netiquette. }\end{array}$ \\
\hline $\begin{array}{c}\text { 4. Creation of content } \\
\text { and knowledge }\end{array}$ & Cognitive area & $\begin{array}{l}\text { Construction of new knowledge through technology and media. } \\
\text { Integrate previous knowledge; construct new knowledge. }\end{array}$ \\
\hline $\begin{array}{c}\text { 5. Ethics and } \\
\text { responsibility }\end{array}$ & $\begin{array}{l}\text { Intersection of Social and } \\
\text { Cognitive areas }\end{array}$ & Behave in an ethical and responsible way, aware of legal frame. \\
\hline $\begin{array}{c}\text { 6. Evaluation and } \\
\text { problem solving }\end{array}$ & $\begin{array}{l}\text { Integrated - Technological, } \\
\text { Cognitive and Social areas }\end{array}$ & $\begin{array}{l}\text { Identify digital needs, solve problems through digital means, and } \\
\text { assess the information retrieved. }\end{array}$ \\
\hline 7. Technical Operations & Technological area & Use technology and media, perform tasks through digital tools. \\
\hline
\end{tabular}

Table 3. A Change Agentry-based Digital Competence Archetypes in PME Context

\begin{tabular}{|c|c|c|c|}
\hline & \multicolumn{3}{|c|}{ Overarching Labels of Different Archetype Conceptualizations } \\
\hline DC Archetype & Technical Expert & Organizer & Campaigner \\
\hline $\begin{array}{l}\text { Parallel } \\
\text { conceptualization }\end{array}$ & $\begin{array}{l}\text { - Traditional model [27] } \\
\text { - Expert type [20] }\end{array}$ & $\begin{array}{l}\text { - Facilitator model [27] } \\
\text { - Facilitator archetype [20] } \\
\text { - Political/marketing campaigns [21] }\end{array}$ & $\begin{array}{l}\text { - Advocate model [27] } \\
\text { - Social warrior archetype [20] } \\
\text { - Military campaign [21] }\end{array}$ \\
\hline $\begin{array}{l}\text { Overlapping key } \\
\text { characteristics }\end{array}$ & $\begin{array}{l}\text { 1. Focuses on technical } \\
\text { expertise; } \\
\text { 2. Detached from } \\
\text { stakeholders' } \\
\text { objectives; } \\
\text { 3. Responsible for } \\
\text { technical aspects only; } \\
\text { 4. Works with minimal } \\
\text { contact from } \\
\text { stakeholders. }\end{array}$ & $\begin{array}{l}\text { 1. Focuses on stakeholders support; } \\
\text { 2. Serves stakeholders' objectives; } \\
\text { 3. Helps stakeholders increase their } \\
\text { capacity for change and autonomy; } \\
\text { 4. Provides learning advice; } \\
\text { 5. Is responsible of changing the } \\
\text { stakeholder's behaviors; } \\
\text { 6. Instructs stakeholders in making } \\
\text { informed decisions; } \\
\text { 7. Tries to gain consensus; } \\
\text { 8. Is organized and flexible. }\end{array}$ & $\begin{array}{l}\text { 1.Uses tactics (e.g. persuasion, } \\
\text { manipulations, power) to } \\
\text { attain his objective; } \\
\text { 2. Responsible for attaining } \\
\text { change objectives; } \\
\text { 3. Makes decisions to guide the } \\
\text { change effort in a particular } \\
\text { direction; } \\
\text { 4.Focuses on objectives. } \\
\text { 5.Is well organized, and } \\
\text { focuses on objectives. }\end{array}$ \\
\hline
\end{tabular}


It would rather mean that it is the technological area that would "dominate" over the other. The same logic can be applied to the "organizer" and the "campaigner" types of change agent. The above review suggests that only a few distinct conceptualizations of change agent exist, and they have significant similarities.

While these conceptualizations of change agent provide interesting visions of digital competence archetypes, they are somewhat general and simplistic, as the overlapping characteristics they identify do not provide a broad conceptual perspective of the DC underlying each change agent type. Furthermore, even if these change agent models could probably be used to characterize the DC of SME employees, they have not been specifically developed for the context of SME. Moreover, they are not sufficiently granular to use the proposed DC conceptualization (see Figure 1) in order to characterize the knowledge, skills and attitude of each change agent conceptualization. While conceptualizing DC archetypes theoretically is intuitively appealing, their inherent lack of specificity also makes them difficult to be empirically tested. An alternative approach would be to identify DC archetypes of SME employees empirically [34]. The present study is an initial attempt in that direction, and to do so, the DC conceptualization (Figure 1) is used as a "property space" to empirically identify existing DC archetypes of SME employees [17].

\section{Methodology}

Empirically identifying DC archetypes based upon perceptions of experienced SME employees provides a viable approach [29]. Since we are in the exploratory phase of theory development where "how" research questions are being asked, a field study using case studies represents an appropriate strategy because it helps in defining the appropriate research design and data collection method but also serves as "the main vehicle for generalizing the results of the case study" $[35, \mathrm{p} .40]$.

In order to collect data, a multi-case study of three SMEs (Palazzo, Knitware and Nylonia - not their real name) from the clothing industries have been carried out between May and September 2014. In each case study, five to nine individuals have been interviewed (before and after the ICT training and the adoption of ICT) including: the SME owners, the HR and ICT managers, as well as other representative employees. The interviews were semi-structured. The questions are based on the key elements of the DC conceptualization (Figure 1 and Table 2) as well as on questions developed by other researchers $[11,19]$.
The interview protocol comprises questions about: the company and its position within the industry; the internal evolution of ICT and its impact on the business processes; the learning domains and the competence areas; the DC development and training as well as the organizational culture and organizational support.

The analysis goals are to assess the usefulness and relevance of the DC conceptualization, investigate the existence of and the dimensions of DC archetypes of SME employees, and identify their relationship with ICT adoption and use. Because of the exploratory nature of the research and the complexity of the investigated phenomenon, the analysis will focused on the dynamics within cases and across cases in order to build an DC typology from case studies [14, 35]. As such, this theory building process is particularly relevant for studies where a priori constructs are triangulated by multiple case studies and where withincase and cross-case analyses are combined with the literature $[14,29]$. Data collection and data analysis had overlap in order to make adjustment during the data collection $[14,35]$.

\section{Findings}

\subsection{Case 1 Palazzo: Technical + Campaigner}

Palazzo is a 450 employees company specialized in the manufacturing and retail clothing and competes in an industry segment characterized by continuous change and strong competition from Asian counterparts. In the past six months, the company has implemented a new integrated ICT platform (Lectra) for their automated sewing machines. In order to ensure a smooth transition from the legacy technology to the new one, the company needs to understand what type of digital competence its employees need to possess. We interviewed six Palazzo employees (three managers: production, ICT, and HR, and three sewing workers - pattern technicians) in May 2014. Interview data analysis points to the existence of digital competences based on two of the four DC areas: social and technological areas (Figure 2).

The interview data suggest the DC archetype Campaigner is strongly embodied by the production manager. She develops and engages her technological and social relational skills to introduce the new ICT that would support Palazzo's continuous development strategy to increase the competitiveness of the company.

"Provide the proper working tools. Evaluate the needs. Identify who can address the needs. Send him/her to training. Some already had the training: you just have to find the right job 
position for them. Find the right time to move the employee to a new job position or get him/her to change his work practices." (Production manager)

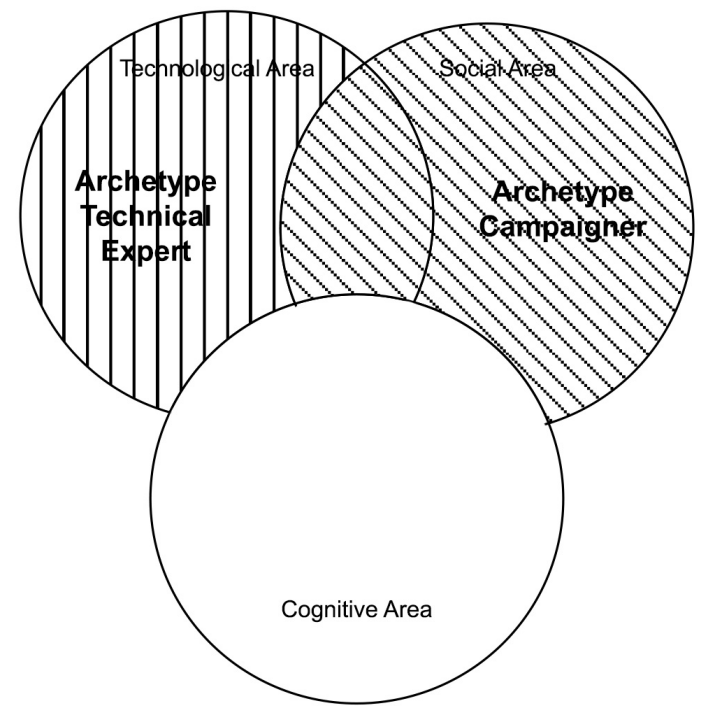

Figure 2. Palazzo Case: Campaigner and Technical Expert Archetypes

Our analysis indicates that the DC archetype that characterizes the three pattern technicians is the Technical expert. They focus on the technical expertise and work in collaboration with their colleagues. However this collaboration is rather limited to exchanging information on how to use the system:

"Once a new technology has been introduced, we get training. And then, after most of the people get trained, the ones that are more competent will be able to train some other employees [...] As soon as we discover something we will share it. We would say: 'oh look, I found a new function, it works like that, what do you think about it?' Then, we will share it among us." (Pattern technician)

The preliminary analysis suggests a relationship between the archetypes Campaigner (Production manager), characterized by strong social and some technical knowledge, skills and attitudes, and Technical expert (Pattern technicians), illustrated by learning domains exclusively related to the technological area of the digital competence. While the development of DC at Palazzo apparently was based only on a mix of technological competence (ICT use as a working tool and for problem solving) and a strong social competence (relational skills to nurture organizational goals that respect internal norms and quality standards), we conjecture that the inclusion of the cognitive DC area is a key factor for a successful adoption of the new ICT.

\subsection{Case 2 Knitware: Technical + Campaigner + Organizer}

Knitware is a family-owned company operating in the field of clothing wholesale distribution, specifically in the business of knitting and employs 40 people. The fabrics come from Italy and Egypt, while the products are designed in Canada and produced in the company owned workshops in China for over 30 years. In August 2014, Knitware launched their online store in order to reach a new market. However just prior to this, the company had to implement a customer relationship management system (Inbiz) linked with the existing point-of-sale (POS) system. We interviewed nine Knitware employees in June and July 2014. Data analysis points to the existence of digital competences based on all the three competence areas (Figure 3 ).

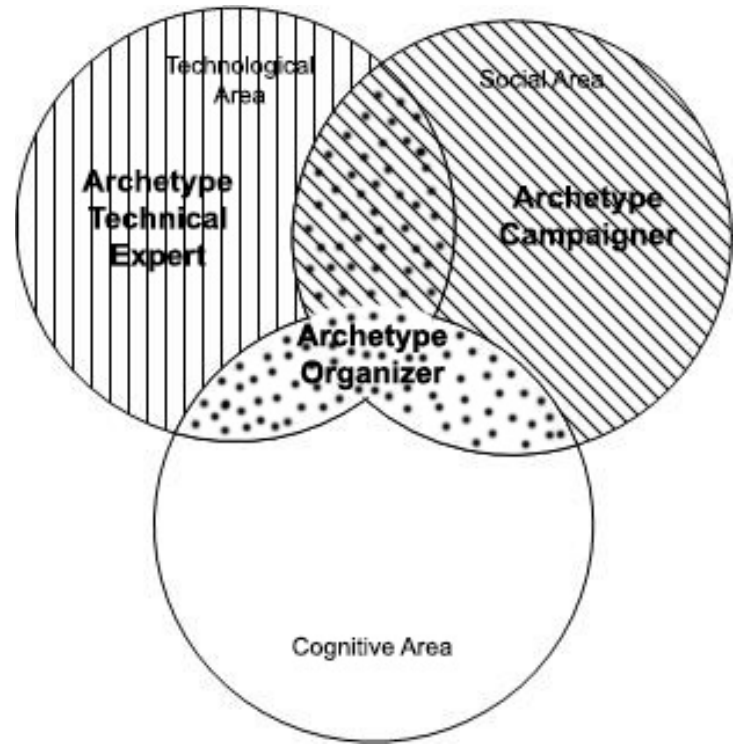

Figure 3. Knitware Case: Organizer, Campaigner and Technical Expert Archetypes

The interview data imply that the Technical expert, the Campaigner and the Organizer are present at Knitware. The warehouse clerk who has interest in all technologies and has a good understanding all Knitware's business processes illustrates the Technical Expert archetype. He self-learned the technology and, with its understanding of the company, he made useful improvements in the systems. He became the de-facto ICT 'expert'.

"I was very much accustomed with the warehouse and the POS. I became the key resource for these 
systems because I understood how to do reports and the inventory. I was able to master all the functionalities of those systems" (Warehouse clerk)

At Knitware, different individuals embodied the Campaigner archetype. Each of these individuals are in charge or responsible of various sectors of the company, e.g. design, distribution, production, boutiques, accounting. Thus, each of them is promoting its own preoccupations and interests regarding the new upcoming system.

"Family is family, so sometimes individuals are squabbling like any family, but it gives us even more the feeling of being part of the family. However, it allows clarifying things and helps having a better understanding of the organization. Honestly, everyone means great and like I said, we're really involved." (General manager)

Finally, the Organizer archetype role was 'played' by the owner's daughter who had worked in the company for the past 10 years, who knows very well the products and organizational processes and who was appointed, by his father (the owner), as the responsible for all the ICT projects. She did not have any specific technical competences before taking on this role but she read and learned about various ICT affordances. She also assisted to professional ICT conferences and surrounded herself with specialists. She became the 'hub' of the company in terms of ICT. She plays an orchestrating role between individuals.

"She is the one most interested with ICT [...] she began to understand, to seek, to always push for us to be on the cutting edge of technology, [...] She surrounded herself with a team of young people comfortable with ICT." (Staff coordinator)

The data analysis point to a central role of the Organizer archetype characterized by social knowledge, skills and attitudes, but also by technological interest and understanding of the ICT affordances. The Organizer was the convergence point of Knitware in terms of ICT. The data also suggest the existence of a complementarity of the competences of each individual. This may explain why Knitware is doing so well in terms of ICT adoption and use. The company manages to capitalize on this complementarity by using several 'bonding' mechanisms (e.g. regular meetings, internal use of social media - Yammer -, roles exchange, etc.) but also by having a resource (the Organizer) in charge of knowing each individual's DC competence in the organization and orchestrating the proper deployment and use of theses competences.

\subsection{Case 3 Nylonia: Technical + Campaigner}

Nylonia is a family-owned business in the hosiery and sock mills sector and employs 100 people. It is specialized in high performance tights and competition apparel (e.g., dance and figure skating clothing). We interviewed five employees in September 2014. Data analysis suggests the existence of digital competences based on only two competence areas (Figure 4) and shows that the Campaigner archetype is strongly embodied by the general manager. However, compared to Cases 1 and 2, here the Campaigner lacks the basic technical skills to understand the actual ICT status in the company.

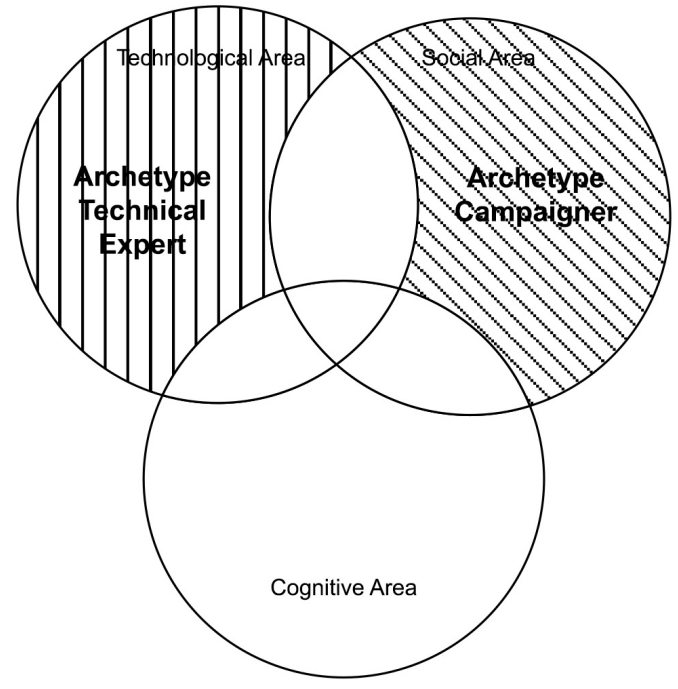

Figure 4. Nylonia Case: Campaigner and Technical Expert Archetypes

In this organization, the president/owner is in his $50 \mathrm{~s}$, and he delegates most the managerial responsibility to the general manager who uses his hierarchical position, his seniority and his social relational skills to promote and justify the need for a web-based e-commerce solution. However, he does not seem to understand the technical challenges to integrate a transactional web-based system within a technological legacy-based environment (old mainframe AS400 developed in the 70s-80s).

"He knows the organization well, he is wellintentioned. However, he does not seem to understand that the technological heart of the company, the AS400, is old and not flexible" (Sales/customer service manager).

Our analysis indicates that the two managers reporting to the general manager (the production/HR and the 
sales/customer service) are the illustration of Technical expert. They know very well the people, the tasks and the technology related to the organizational areas under their responsibility. However, they lack the understanding of the rest of the organization as well as the general manager's intentions regarding ICT projects. They have not been really informed or consulted regarding those projects. The communication between departments and hierarchical levels is deficient.

"My team is open and ready. We want new technologies to be more efficient and up-to-date, but we have no idea what's coming and where we are heading" (Customer service manager).

\section{Conclusions and Future Research}

The literature suggests that SMEs create value through ICT innovation, which represents the firms' ability to be resourceful and capture the value-creating opportunities presented by the growth of ICT and its usage [33]. In this vein, Chircu and Kauffman [10] find that lack of ability to acquire skill and expertise in new ICT combined with a lack of training and education form significant barriers to the adoption of ICT. In the context of SMEs, the organizations that have employees with the proper DC are more likely to accept innovations as they have a better understanding of the benefits of such innovations than if such competences were lacking [8].

While DC is regarded as a core competence, it is not yet a standardized concept in the ICT literature in general and on SMEs in particular. The need for a conceptual model to assess DC in a SME environment is based on recent literature that suggests that: small businesses need to adopt ICT strategies to keep up with the new economy; and successful innovation in this organizational context depends heavily on investments made in ICT platforms, the success of which, in turn, depends on employees having the appropriate ICT skills [22]. The present article addresses the lack of a clear understanding of what DC is by proposing a definition and a conceptual framework. This study suggests that DC represents a set learning domains, i.e. knowledge, skills and attitudes (including abilities, strategies, values and awareness), related to three competence areas, i.e. technological, social and cognitive, that are required when using ICT in an organizational context to: 1) perform tasks and solve problems; 2) communicate, assess and manage digital information; 3) collaborate to create and share knowledge; and 4) build knowledge effectively and efficiently for sustaining successful organizational practices.
We also advance a typology of key DC archetypes in the context of SME. Based on findings from three SMEs we identify three DC archetypes: Campaigner, Organizer and Technical Expert. These results confirm Harison and Boonstra's [19] study outcomes by suggesting that development of efficient DC is linked to the existence of organizational competences to successfully manage organizational change.

By testing our conceptual framework in three different SMEs, we observed that it is virtually impossible that a single individual possesses all the required knowledge, skills and attitudes in all the competence domains. More importantly, we observed that it is not the universality of DC (i.e., a single individual possessing all the required DC dimensions) that is imperative in an SME, but rather the complementarity of its three competence areas. Thus, we posit that in order to improve ICT adoption and use, SMEs need to have individuals mastering learning domains in one or two of the three DC areas and at least an individual (the Organizer) having enough knowledge, skills and attitudes to acquire a three-area complimentary DC that would reflect the needs of the specific organizational context. This combination will eventually trigger the emergence of appropriate organizational competences and processes, which would facilitate effective adoption and successful use of ICT. This study with its focus on the multidimensional nature of $\mathrm{DC}$ is well timed. While providing only exploratory results in a specific geographically area and industry, this study offers enough pertinent information to policy makers and industry leaders wishing to understand some of the reasons why certain SMEs lag in the adoption of ICT and related technologies. Hopefully, ICT local vendors and financial institutions in areas where efforts are made to strengthen SMEs' e-business aspirations may benefit from the results of our study.

\section{Acknowledgement}

This study is part of a larger research program SME 2.0, funded by the Government of Quebec and coordinated by CEFRIO with the scope of documenting and fostering the adoption of ICT in Quebec SMEs.

\section{References}

[1] K. Ala-Mutka, Mapping Digital Competence: Towards a Conceptual Understanding, Publications Office of the European Union, 2011.

[2] C. Ashurst, P. Cragg and P. Herring, "The role of IT competences in gaining value from e-business: An SME case 
study", International Small Business Journal, 30 (2012), pp. 640-658

[3] B. J. Bashein and M. L. Markus, "A Credibility Equation for IT Specialists", Sloan Management Review (1997), pp. $35-44$.

[4] G. Bassellier and I. Benbasat, "Business Competence of IT Professionals: Conceptual Development and Influence on IT-Business Partnerships", MIS Quarterly, 28 (2004), pp. 673-694.

[5] G. Bassellier, R. Blaize Horner and I. Benbasat, "Information technology competence of business managers: A definition and research model", Journal of Management Information Systems, 17 (2001), pp. 9-182.

[6] S. Bruque and J. Moyano, "Organizational Determinants of Information Technology Adoption and Implementation in SMEs: The Case of Family and Cooperative Firms", Technovation, 27 (2007), pp. 241-253.

[7] A. Burton-Jones and C. Grange, "From Use to Effective Use: A Representation Theory Perspective", Information Systems Research, 24 (2013), pp. 632-658.

[8] M. M. Caldeira and J. M. Ward, "Understanding the Successful Adoption and Use of IS/IT in SMEs: An Explanation from Portuguese Manufacturing Industries", Information Systems Journal, 12 (2002), pp. 121-152.

[9] A. Calvani, A. Cartelli, A. Fini and M. Ranieri, "Models and instruments for assessing digital competence at school", Journal of e-Learning and Knowledge Society, 4 (2008), pp. 183-193.

[10] A. M. Chircu and R. J. Kauffman, "Limits to value in electronic commerce-related IT investments", Journal of Management Information Systems, 17 (2000), pp. 59-80.

[11] P. Cragg, M. Caldeira and J. Ward, "Organizational information systems competences in small and medium-sized enterprises", Information \& Management, 48 (2011), pp. 353-363.

[12] C. Dibrell, P. S. Davis and J. Craig, "Fueling innovation through Information Technology in SMEs", Journal of Small Business Management, 46 (2008), pp. 203-218.

[13] D. H. Doty and W. H. Glick, "Typologies as a Unique Form of Theory Building: Toward Improved Understanding and Modeling", Academy of Management Review, 19 (1994), pp. $230-251$

[14] K. M. Eisenhardt, "Building Theories from Case Study Research", Academy of Management Review, 14 (1989), pp. 532-550.

[15] A. Ferrari, Digital Competence in Practice: An Analysis of Frameworks, Publications Office of the European Union, 2012.

[16] I. Fillis and B. Wagner, "E-business development: An exploratory investigation of the small firm", International Small Business Journal, 23 (2005), pp. 604-634.

[17] A. L. George and A. Bennett, Case Studies and Theory Development in Social Sciences, MIT Press, Cambridge, Massachusetts, 2005.

[18] S. Gregor, "The Nature of Theory in Information Systems", MIS Quarterly, 30 (2006), pp. 611-642.

[19] E. Harison and A. Boonstra, "Essential competencies for technochange management: Towards an assessment model", International Journal of Information Management, 29 (2009), pp. 283-294.
[20] R. Hirschheim and H. K. Klein, "Four Paradigms of Information Systems Development", Communications of the ACM, 32 (1989), pp. 1199-1216.

[21] L. Hirschhorn, "Campaigning for Change", Harvard Business Review, 80 (2002), pp. 98-104.

[22] P. Ifinedo, "Internet/e-business technologies acceptance in Canada's SMEs: an Exploratory Investigation", Internet Research, 21 (2011), pp. 255-281.

[23] International ICT Literacy Panel, Digital Transformation. A Framework for ICT Literacy, Educational Testing Service, 2002.

[24] D. Jones-Evans, "Technical entrepreneurship, strategy and experience", International Small Business Journal, 14 (1996), pp. 15-39.

[25] R. Lamb and R. Kling, "Reconceptualizing users as social actors in information systems research", MIS Quarterly, 27 (2003), pp. 197-235.

[26] B. L. Marcolin, D. R. Compeau, M. C. Munro and S. L. Huff, "Assessing User Competence: Conceptualization and Measurement", Information Systems Research, 11 (2000), pp. 37-60.

[27] M. L. Markus and R. I. Benjamin, "Change Agentry the Next IS Frontier", MIS Quarterly, 20 (1996), pp. 385407.

[28] Oxford English Dictionary, Oxford University Press, 2013.

[29] M. Q. Patton, Qualitative Research \& Evaluation Methods, Sage Publications, Thousand Oaks, California, 2002.

[30] P. A. Pavlou and O. A. El Sawy, "From IT Leveraging Competence to Competitive Advantage in Turbulent Environments: The Case of New Product Development", Information Systems Research, 17 (2006), pp. 198-227.

[31] S. Rivard, "Editor's Comments: The Ions of Construction", MIS Quarterly, 38 (2014), pp. iii-xiii.

[32] V. Seppanen, "Evolution of competence in software contracting projects", International Journal of Project Management, 20 (2002), pp. 155-164.

[33] J. Tidd, J. Bessant and K. Pavitt, Managing Innovation: Integrating Technological, Market And Organisational Change,, John Wiley, 2005.

[34] N. Venkatraman, "The Concept of Fit in Strategy Research: Toward Verbal and Statistical Correspondence", Academy of Management Review, 14 (1989), pp. 423-444.

[35] R. K. Yin, Case Study Research: Design and Methods, SAGE Publication, Thousand Oaks, CA, 2009. 